\title{
THE GALACTIC CENTER: THE LARGEST OXYGEN-BEARING ORGANIC MOLECULE REPOSITORY
}

\author{
M. A. Requena-Torres, ${ }^{1}$ J. Martín-Pintado, ${ }^{1}$ S. Martín, ${ }^{2}$ and M. R. Morris ${ }^{3}$ \\ Received 2007 March 27; accepted 2007 August 30
}

\begin{abstract}
We present the first detection of complex aldehydes and isomers in three typical molecular clouds located within $200 \mathrm{pc}$ of the center of our Galaxy. We find very large abundances of these complex organic molecules (COMs) in the Central Molecular Zone (CMZ), which we attribute to the ejection of COMs from grain mantles by shocks. The relative abundances of the different $\mathrm{COMs}$ with respect to that of $\mathrm{CH}_{3} \mathrm{OH}$ are strikingly similar for the three sources, which are located in very different environments in the CMZ. The similar relative abundances point toward a unique grain mantle composition in the CMZ. Studying the Galactic center clouds and objects in the Galactic disk having large abundances of COMs, we find that more saturated molecules are more abundant than the nonsaturated ones. We also find differences between the relative abundance between COMs in the CMZ and the Galactic disk, suggesting different chemical histories of the grain mantles between the two regions in the Galaxy for the complex aldehydes. Different possibilities for the grain chemistry on the icy mantles in the GC clouds are briefly discussed. Cosmic rays can play an important role in the grain chemistry. With these new detections, the molecular clouds in the Galactic center appear to be one of the best laboratories for studying the formation of COMs in the Galaxy.
\end{abstract}

Subject headings: astrochemistry — ISM: individual (CMZ) — ISM: molecules — molecular data — techniques: spectroscopic

Online material: color figures

\section{INTRODUCTION}

It has been found that complex organic molecules (COMs) are very abundant in the Galactic center (GC; Martín-Pintado et al. 2001; Requena-Torres et al. 2006, hereafter Paper I), where the molecular gas is concentrated in the Central Molecular Zone (CMZ; Morris \& Serabyn 1996). Large COMs in the Galaxy have been mainly associated with hot cores (e.g., Ikeda et al. 2001), where they are evaporated from icy mantles of warm dust $(>100 \mathrm{~K})$ heated by massive protostars. The physical conditions in the $\mathrm{CMZ}$ are very different from those in hot cores. High gaskinetic temperatures of $>100 \mathrm{~K}$, but low-excitation temperatures $\sim 10-20 \mathrm{~K}$ due to the relatively low $\mathrm{H}_{2}$ densities (few $10^{4} \mathrm{~cm}^{-3}$ ) and cold dust of $T_{d}<20 \mathrm{~K}$ (Rodríguez-Fernández et al. 2000) are typical in the CMZ. Since the dust is too cold for the evaporation of the ice mantles, it has been proposed that the sputtering of the grains and grain mantles produced by widespread shocks is responsible for the rich chemistry and the high temperatures observed in the CMZ (Martín-Pintado et al. 1997; Hüttemeister et al. 1998; Chengalur \& Kanekar 2003; Paper I). In spite of the different physical conditions in hot cores and GC clouds, Paper I shows that the abundances of the COMs $\left(\mathrm{C}_{2} \mathrm{H}_{5} \mathrm{OH}, \mathrm{CH}_{3} \mathrm{OCH}_{3}, \mathrm{HCOOCH}_{3}\right.$, and $\mathrm{HCOOH}$ ) relative to that of $\mathrm{CH}_{3} \mathrm{OH}$ (methanol) are surprisingly similar for both types of sources, suggesting a sort of "universal" grain mantle composition in the Galactic disk and in the CMZ.

Recently, even larger COMs like the aldehydes propynal $\left(\mathrm{HC}{ }_{2} \mathrm{CHO}\right)$, propenal $\left(\mathrm{CH}_{2} \mathrm{CHCHO}\right)$, propanal $\left(\mathrm{CH}_{3} \mathrm{CH}_{2} \mathrm{CHO}\right)$, and glycolaldehyde $\left(\mathrm{CH}_{2} \mathrm{OHCHO}\right)$ and complex alcohols like ethylene glycol $\left(\mathrm{HOCH}_{2} \mathrm{CH}_{2} \mathrm{OH}\right)$ have been detected toward one star-forming region in the CMZ, Sgr B2N (Dickens et al.

\footnotetext{
1 Departamento de Astrofísica Molecular e Infrarroja- Instituto de Estructura de la Materia-CSIC, C Serrano 121,E-28006 Madrid, Spain; requena@damir.iem .csic.es, martin@damir.iem.csic.es.

2 Harvard-Smithsonian Center for Astrophysics, 60 Garden Street, MS 78 Cambridge, MA 02138; martin@astro.cfa.edu.

3 Department of Physics and Astronomy, University of California, Los Angeles, CA 90095-1547; morris@astro.ucla.edu.
}

2001; Hollis et al. 2000, 2002, 2004b). The proposed formation paths for the COMs on grains include the hydrogenation, oxidation, and/or carbon addition of small molecules on grain mantles (Tielens \& Hagen 1982; Charnley \& Rodgers 2005). Carbon addition on grain mantles has been studied by Jamieson et al. (2006), but it is unclear if these reactions are as efficient as predicted. Hiraoka et al. (2002), Watanabe (2005), and Fuchs et al. (2007) have shown that the hydrogenation of CO can efficiently produce $\mathrm{H}_{2} \mathrm{CO}$ and $\mathrm{CH}_{3} \mathrm{OH}$. Reactions of radicals on grain surfaces constitute another hypothesis for forming large molecules (Greenberg 1976; Garrod \& Herbst 2006; Garrod et al., in preparation). Recently Bennett \& Kaiser (2007) have formed the isomers $\mathrm{CH}_{2} \mathrm{OHCHO}$ and $\mathrm{HCOOCH}_{3}$ on grain mantle analogs by irradiation of a mixture of $\mathrm{CH}_{3} \mathrm{OH}$ and $\mathrm{CO}$ ices at $10 \mathrm{~K}$ with energetic electrons to mimic the effects of the cosmic rays. Finally, Halfen et al. (2006) showed that in the Sgr B2N hot core, the formation of $\mathrm{CH}_{2} \mathrm{OHCHO}$ from $\mathrm{H}_{2} \mathrm{CO}$ in the gas phase may be possible. So far, most of our knowledge of these COMs is restricted to one source, the Sgr B2N hot core, which has a very complex core-halo structure (Martín-Pintado et al. 1990; Hollis et al. 2004a) making it very difficult to establish where (hot core vs. envelope) these molecules are formed.

In this paper, we present the first detections of most of the largest COMs, previously observed only toward Sgr B2N, in typical molecular clouds in the CMZ without signatures of star formation. These observations show that the $\mathrm{GC}$ is one of the best laboratories for understanding the chemistry of COMs and support the idea of a similar grain mantle composition throughout the CMZ, but this does not extend to the Galactic disk.

\section{OBSERVATIONS AND RESULTS}

Observations were carried in April and May of 2006 with the NRAO $^{4} 100$ m Robert C. Byrd Green Bank Telescope in West

\footnotetext{
4 The National Radio Astronomy Observatories is a facility of the National Science Foundation, operated under a cooperative agreement by Associated Universities, Inc.
} 
TABLE 1

Observed Frequencies

\begin{tabular}{|c|c|c|c|}
\hline Molecule & Transition & $\begin{array}{c}\text { Frequency } \\
(\mathrm{MHz})\end{array}$ & $\begin{array}{c}E_{u} \\
(\mathrm{~K})\end{array}$ \\
\hline $\mathrm{H}_{2} \mathrm{COH}^{+} \ldots \ldots \ldots$ & $2_{1,1} \rightarrow 2_{1,2}$ & $15532.99^{\mathrm{a}}$ & 17.49 \\
\hline $\mathrm{CH}_{3} \mathrm{CH}_{2} \mathrm{CH}_{2} \mathrm{OH}^{*} \ldots \ldots \ldots \ldots \ldots$ & $6_{15} \rightarrow 6_{0,6}$ & $20339.80^{\mathrm{a}}$ & 10.30 \\
\hline $\mathrm{CH}_{2} \mathrm{OHCHO}$ & $1_{1,0} \rightarrow 1_{0,1}$ & $13477.17^{\mathrm{a}}$ & 1.20 \\
\hline $\mathrm{CH}_{2} \mathrm{OHCHO}$ & $2_{1,1} \rightarrow 2_{0,2}$ & $15176.46^{\mathrm{a}}$ & 2.38 \\
\hline 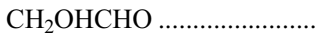 & $4_{1,3} \rightarrow 3_{2,2}$ & $15261.66^{\mathrm{a}}$ & 6.48 \\
\hline $\mathrm{CH}_{2} \mathrm{OHCHO}$ & $4_{1,3} \rightarrow 4_{0,4}$ & $22142.67^{\mathrm{a}}$ & 6.48 \\
\hline $\mathrm{HOCH}_{2} \mathrm{CH}_{2} \mathrm{OH} \ldots \ldots \ldots \ldots$ & $3_{0,3}(v 0) \rightarrow 2_{0,2}(v 1)$ & $23393.10^{\mathrm{a}}$ & 2.92 \\
\hline $\mathrm{HOCH}_{2} \mathrm{CH}_{2} \mathrm{OH} \ldots \ldots \ldots \ldots$ & $2_{0,2}(v 0) \rightarrow 1_{0,1}(v 1)$ & $13380.60^{\mathrm{a}}$ & 1.47 \\
\hline $\mathrm{HC}_{2} \mathrm{CHO}$ & $2_{0,2} \rightarrow 1_{0,1}$ & $18650.31^{\mathrm{c}}$ & 1.34 \\
\hline $\mathrm{HC}_{2} \mathrm{CHO}^{*}$ & $2_{1,1} \rightarrow 1_{1,0}$ & $18978.78^{\mathrm{c}}$ & 4.41 \\
\hline $\mathrm{CH}_{2} \mathrm{CHCHO} \ldots \ldots \ldots$ & $2_{1,1} \rightarrow 1_{1,0}$ & $18221.16^{\mathrm{c}}$ & 3.37 \\
\hline $\mathrm{CH}_{2} \mathrm{CHCHO} \ldots \ldots \ldots$ & $3_{1,3} \rightarrow 2_{1,2}$ & $26079.45^{\mathrm{c}}$ & 4.56 \\
\hline $\mathrm{CH}_{3} \mathrm{CH}_{2} \mathrm{CHO}$ & $2_{1,2} \rightarrow 1_{1,1}$ & $19690.43^{\mathrm{c}}$ & 1.97 \\
\hline $\mathrm{CH}_{3} \mathrm{CH}_{2} \mathrm{CHO} \ldots \ldots \ldots \ldots$ & $3_{0,3} \rightarrow 2,1$ & $21451.57^{\mathrm{c}}$ & 3.00 \\
\hline $\mathrm{CH}_{3} \mathrm{OH}$ & $3_{2,3} \rightarrow 3_{1,3}$ & $24928.70^{\mathrm{a}}$ & 36.18 \\
\hline $\mathrm{CH}_{3} \mathrm{OH}$ & $4_{2,3} \rightarrow 4_{1,3}$ & $24933.47^{\mathrm{a}}$ & 45.46 \\
\hline $\mathrm{CH}_{3} \mathrm{OH}$ & $2,3 \rightarrow 2,3$ & $24934.38^{\mathrm{a}}$ & 29.21 \\
\hline $\mathrm{CH}_{3} \mathrm{OH}$ & $5_{2,3} \rightarrow 5_{1,3}$ & $24959.08^{\mathrm{a}}$ & 57.07 \\
\hline $\mathrm{CH}_{3} \mathrm{OH}$ & $6_{2,3} \rightarrow 6_{1,3}$ & $25018.12^{\mathrm{a}}$ & 71.01 \\
\hline $\mathrm{HCOOCH}_{3}-\mathrm{A}$ & $2_{1,1} \rightarrow 1_{1,0}$ & $26048.52^{\mathrm{a}}$ & 2.54 \\
\hline $\mathrm{HCOOCH}_{3}-\mathrm{E} \ldots \ldots \ldots$ & $2_{1,1} \rightarrow 1_{1,0}$ & $26044.83^{\mathrm{a}}$ & 2.56 \\
\hline $\mathrm{CH}_{3} \mathrm{CHO}-\mathrm{A}^{*} \ldots \ldots \ldots \ldots \ldots$ & $1_{0,1} \rightarrow 0_{0,0}$ & $19265.16^{\mathrm{b}}$ & 0.93 \\
\hline $\mathrm{CH}_{3} \mathrm{CHO}-\mathrm{E}^{*} \ldots \ldots$ & $1_{0,1} \rightarrow 0_{0,0}$ & $19262.16^{\mathrm{b}}$ & 1.02 \\
\hline $\mathrm{H}_{2} \mathrm{CCO}^{*} \ldots \ldots \ldots \ldots \ldots \ldots$ & $1_{0,1} \rightarrow 0_{0,0}$ & $20209.20^{\mathrm{a}}$ & 0.97 \\
\hline $\mathrm{c}-\mathrm{C}_{2} \mathrm{H}_{4} \mathrm{O}$ & $2_{1,1} \rightarrow 2_{0,2}$ & $24923.64^{\mathrm{a}}$ & 6.15 \\
\hline
\end{tabular}

Notes.-Transitions observed for each source. The transitions marked with an asterisk $\left({ }^{*}\right)$ have been only observed in $\mathrm{MC} \mathrm{G}+0.693-0.03$.

${ }^{a}$ Spectroscopic characteristics obtained from the Colonia University Database (Müller et al. 2001, 2005).

b Spectroscopic characteristics obtained from Pickett et al. (1998).

${ }^{c}$ Spectroscopic characteristics obtained from Hollis et al. (2004b).

Virginia. Ku-band and K-band receivers were used in connection with the spectrometer divided into four spectral windows of $200 \mathrm{MHz}$ each in both bands. We obtained a resolution of $24.4 \mathrm{kHz}, 0.6 \mathrm{~km} \mathrm{~s}^{-1}$ for the Ku band and $0.3 \mathrm{~km} \mathrm{~s}^{-1}$ for the $\mathrm{K}$ band. Two polarizations were observed for each spectral window through the use of offset oscillators in the intermediate frequencies (IF). The frequencies and the spectroscopic parameters of the observed molecular transitions are shown in Table 1. They were obtained from the Cologne Database for Molecular Spectroscopy (Müller et al. 2001, 2005), the Jet Propulsion Laboratory catalog (Pickett et al. 1998), and Hollis et al. (2004b).

The observed typical molecular clouds are $\mathrm{MC} \mathrm{G}-0.11-0.08$ (the " $20 \mathrm{~km} \mathrm{~s}^{-1}$ cloud") and MC G-0.02-0.07 (the " $50 \mathrm{~km} \mathrm{~s}^{-1}$ cloud") located in the Sgr A* complex and MC G+0.693-0.03 located in the Sgr B2 complex. Those sources were selected from Paper I due to their large column density of COMs. In Table 2 we give for the observed sources the position, the velocity, the $\mathrm{H}_{2}$ column density (derived from the $\mathrm{C}^{18} \mathrm{O}$ emission in Paper I), and the $\mathrm{CH}_{3} \mathrm{OH}$ abundances (also from Paper I). The observations were made using the position-switched mode, with the off position free from emission selected from CS maps (Bally et al. 1987). The two polarization outputs from the spectrometer were averaged in the final data reduction process to improve the signal-tonoise ratio. After smoothing the data, the final resolution was $\sim 3 \mathrm{~km} \mathrm{~s}^{-1}$. Calibration was achieved by using a noise tube, and the line intensities are given in the $T_{\mathrm{A}}^{*}$ scale (estimated with $10 \%-20 \%$ uncertainties), appropriate for extended sources.

Figure 1 shows a sample of the line profiles observed toward the different sources. We obtained detections of almost all the transitions in Table 2. In MC G+0.693-0.03 we were able to obtain the most complete set of transitions, including the HCCCHO $2_{1,1} \rightarrow 1_{1,0}$ line and the additional molecular transitions shown in Figure 2. In this source all the transitions were detected for all molecules except for propanol $\left(\mathrm{C}_{3} \mathrm{H}_{7} \mathrm{OH}\right)$. As shown in Figures 1 and 2, together with the complex aldehydes we also detect or derive upper limits for other related molecules like $\mathrm{CH}_{3} \mathrm{OH}$, $\mathrm{HCOOCH}_{3}$ (methyl formate), $\mathrm{CH}_{3} \mathrm{CHO}$ (acetaldehyde), $\mathrm{H}_{2} \mathrm{CCO}$ (ketene), and c- $\mathrm{C}_{2} \mathrm{H}_{4} \mathrm{O}$ (ethylene oxide). We have also detected $\mathrm{H}_{2} \mathrm{COH}^{+}$, protonated formaldehyde, one of the molecules expected to play a key role in the gas-phase formation of $\mathrm{CH}_{2} \mathrm{OHCHO}$ in hot cores (Ohishi et al. 1996). For completeness, we have also included data of $\mathrm{H}_{2}^{13} \mathrm{CO}$ and $\mathrm{H}_{2} \mathrm{C}^{18} \mathrm{O}$ from Martín et al. (2006) to derive the abundance of the chemically related molecule $\mathrm{H}_{2} \mathrm{CO}$.

\section{ANALYSIS}

We obtained the line parameters shown in Table 3 by fitting Gaussians to the observed line profiles. The column densities for all the molecules were then derived using the local thermodynamic equilibrium (LTE) approximation, and the excitation temperatures, $T_{\mathrm{ex}}$, were derived from the population diagrams when enough rotational lines were available. Figure 3 shows a sample of population diagrams for the three sources. We derived $T_{\text {ex }}$ between 8 and $16 \mathrm{~K}$ for all the sources, similar to those found in Paper I.

The population diagrams for $\mathrm{CH}_{2} \mathrm{OHCHO}$ cannot be fit with a single excitation temperature, indicating non-LTE excitation. This is consistent with the findings of Hollis et al. (2004a) who observed the $2_{1,1} \rightarrow 2_{0,2}$ and the $4_{1,3} \rightarrow 3_{0,4}$ lines in absorption and the $1_{1,0} \rightarrow 1_{0,1}$ in emission toward the Sgr B2N hot core. For our analysis we have used the $1_{1,0} \rightarrow 1_{0,1}$ and $4_{1,3} \rightarrow 3_{2,2}$ emission lines, which yield similar column densities and do not show absorption profiles toward Sgr B2N.

The main source of error in our estimated column densities arises from the assumption of the LTE approximation using the single excitation temperature derived from the population diagrams. However, even in the extreme case that the excitation temperature varies by a factor of 2 , the error introduced by these

TABLE 2

Parameters of the Sources

\begin{tabular}{|c|c|c|c|c|c|}
\hline Source & $\alpha(\mathrm{J} 2000.0)$ & $\delta(\mathrm{J} 2000.0)$ & $\begin{array}{c}\text { Velocity } \\
\left(\mathrm{km} \mathrm{s}^{-1}\right)\end{array}$ & $\begin{array}{l}n\left(\mathrm{H}_{2}\right) \\
\left(\mathrm{cm}^{-2}\right)\end{array}$ & $X\left(\mathrm{CH}_{3} \mathrm{OH}\right)$ \\
\hline MC G-0.02-0.07 & 174551 & -285906 & 47 & $6.8 \times 10^{22}$ & $2.9 \times 10^{-7}$ \\
\hline MC G- $0.11-0.08 \ldots \ldots \ldots$ & 174539 & -290405 & 21 & $1.0 \times 10^{22}$ & $1.1 \times 10^{-6}$ \\
\hline MC G+0.693-0.03 & 174722 & -282127 & 68 & $4.1 \times 10^{22}$ & $4.5 \times 10^{-7}$ \\
\hline
\end{tabular}

Notes.-Units of right ascension are hours, minutes, and seconds, and units of declination are degrees, arcminutes, and arcseconds. Positions, velocities, column densities of $\mathrm{H}_{2}$, and $\mathrm{CH}_{3} \mathrm{OH}$ abundances for the different sources. Data are from Paper I. 


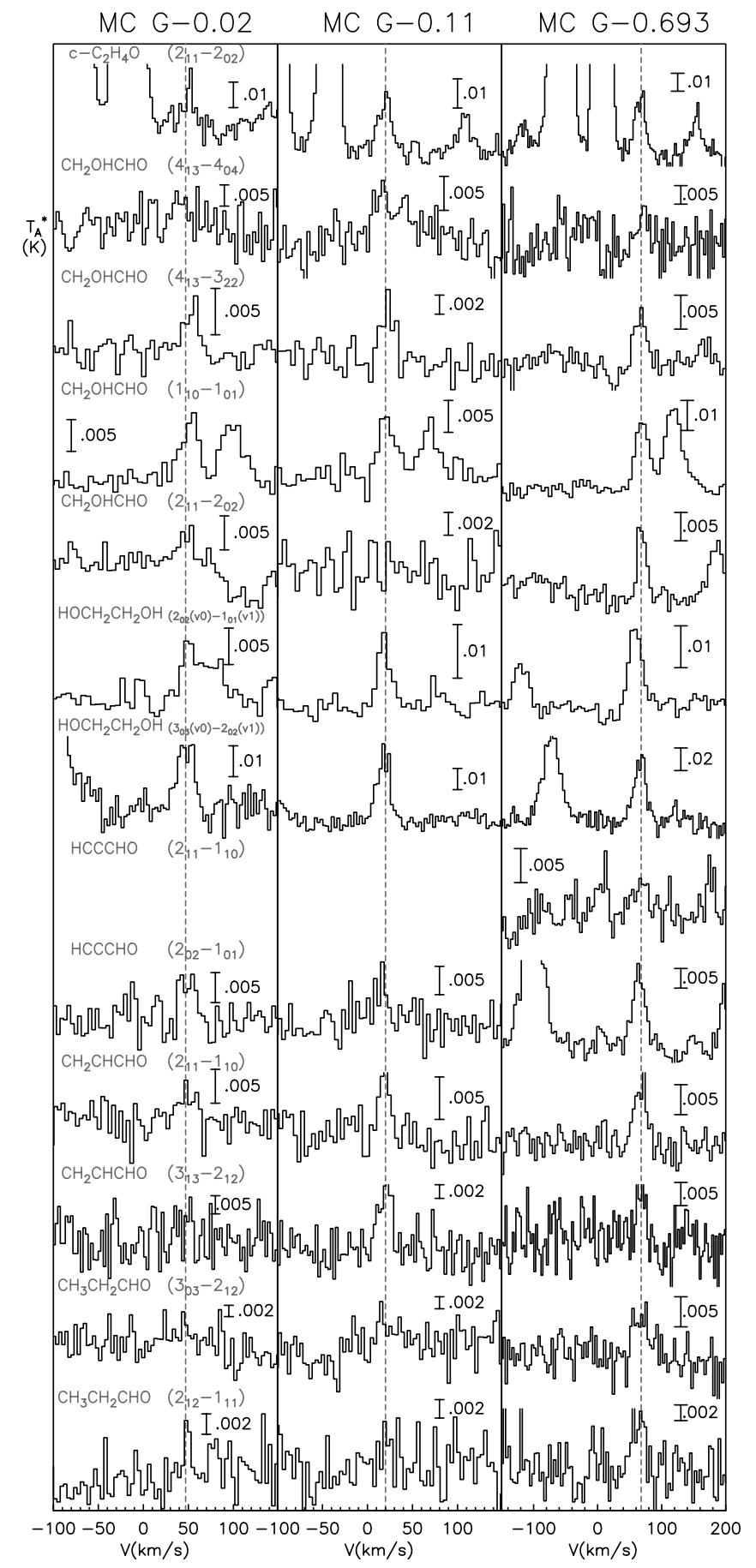

FIG. 1.- Spectra of the molecular transitions observed in all three sources.

uncertainties in our estimated column densities for COMs will be less than a factor of 2 . We therefore consider that our estimation of column densities is uncertain by less than a factor of 2 (see also Paper I). To obtain the relative molecular abundances, we have used the $\mathrm{H}_{2}$ column densities derived in Paper I from the $\mathrm{C}^{18} \mathrm{O}$ emission (see Table 2). The results of the relative abundances of COMs are shown in Table 4.

\section{EXCITATION}

As discussed in Paper I, the COMs in the GC show very low $T_{\text {ex }}$ as compared with those found in hot cores. This is in contrast with the gas kinetic temperatures derived from $\mathrm{NH}_{3}$ and $\mathrm{H}_{2}$, which range from 30 up to $500 \mathrm{~K}$ (Hüttemeister 1993;
Rodríguez-Fernández et al. 2001). On average, 30\% of the molecular gas in the GC has kinetic temperatures of $\gtrsim 100 \mathrm{~K}$. From the analysis of all the data, Rodríguez-Fernández et al. (2001) concluded that the large abundances of $\mathrm{NH}_{3}, \mathrm{SiO}$, and the high kinetic temperatures but low dust temperatures can be explained by C-type shocks with velocities of $10 \mathrm{~km} \mathrm{~s}^{-1}$. The large COM abundances can also be explained by grain mantle sputtering by shocks. Shocks with velocities of $\sim 6 \mathrm{~km} \mathrm{~s}^{-1}$ are very efficient at ejecting molecules from the icy mantles when $\mathrm{CO}$ is considered as the sputtering agent (Jiménez-Serra et al. 2007).

The most likely explanation for the low $T_{\mathrm{ex}}$ derived from the various COMs is that the gas has high kinetic temperatures, but the COMs are subthermally excited due to the relatively low $\mathrm{H}_{2}$ column densities. This has been discussed in detail in Paper I with a similar analysis of the excitation of $\mathrm{CH}_{3} \mathrm{OH}$. Furthermore, if the gas kinetic temperature were on the order of $10-20 \mathrm{~K}$, in equilibrium with the cold dust, then the COMs would be thermalized, requiring $\mathrm{H}_{2}$ densities of $\sim 10^{6} \mathrm{~cm}^{-3}$ (Paper I). From the $\mathrm{H}_{2}$ column densities in Table 2 , the derived size of the molecular cloud along the line of sight would be only $\sim 4.1 \times 10^{16} \mathrm{~cm}$, just 2739 AU. This is unlikely since the COM emission is very extended, so this would require that the GC molecular clouds be very thin sheets perpendicular to the line of sight.

\section{ABUNDANCES AND RELATIVE ABUNDANCES}

We have found very high abundances for all the observed COMs in the CMZ, from $10^{-10}$ to $10^{-8}$ except for $\mathrm{CH}_{3} \mathrm{OH}$, which shows larger relative abundances of a few times $10^{-7}$ to $10^{-6}$. In our previous work on COMs in the CMZ (Paper I), we suggested that this region is affected by the erosion of the dust grain mantles by shocks and that the gas-phase abundances of large COMs may be large if they are formed on grain mantles.

To illustrate the possible differences in chemistry, we present the abundances of the different molecules as ratios with respect to that of $\mathrm{CH}_{3} \mathrm{OH}$ in Table 5 (as in Paper I). Errors in the abundance ratios can be estimated by considering the propagation of the errors in the column densities in each molecule. Uncertainties of a factor of $\lesssim 3$ are expected for these abundance ratios. However, as mentioned in $\S 4$ the main source of uncertainty is the derived $T_{\mathrm{ex}}$, which will affect all $\mathrm{COMs}$ and $\mathrm{CH}_{3} \mathrm{OH}$ in a similar way. In this case a factor of 3 must be considered an upper limit to the uncertainties in our estimated abundance ratios. The relative abundance of every molecule with respect to that of $\mathrm{CH}_{3} \mathrm{OH}$ is rather constant between sources, with changes by only a factor of $\lesssim 3$, similar to the uncertainties. As in Paper I, we find similar abundance ratios for all COMs between sources that are separated by hundreds of parsecs. This remarkable result supports the claim of a similar grain mantle composition in the whole CMZ.

\section{COMPARISON BETWEEN RELATED MOLECULES}

Figure 4 summarizes all the observed COMs in the CMZ sources in this paper and in Paper I following the simplest hypothesis that the formation of COMs on grain mantles is due to additions of O, C, and $\mathrm{H}$ to $\mathrm{CO}$ (Tielens \& Hagen 1982; Charnley $\&$ Rodgers 2005). Chemical complexity starting from CO increases from left to right by adding $\mathrm{C}$, from the center to top and bottom by adding $\mathrm{H}$, and in diagonals by adding $\mathrm{O}$. The radicals are shown within ellipses and the molecular species in boxes. The different families of isomers are shown in the figure enclosed in dashed line boxes. The molecules detected in the GC molecular clouds are highlighted in boldface to distinguished them from the undetected species. To test the scheme proposed in Figure 4, we have compared the relative abundances derived between related 
MC G-0.693
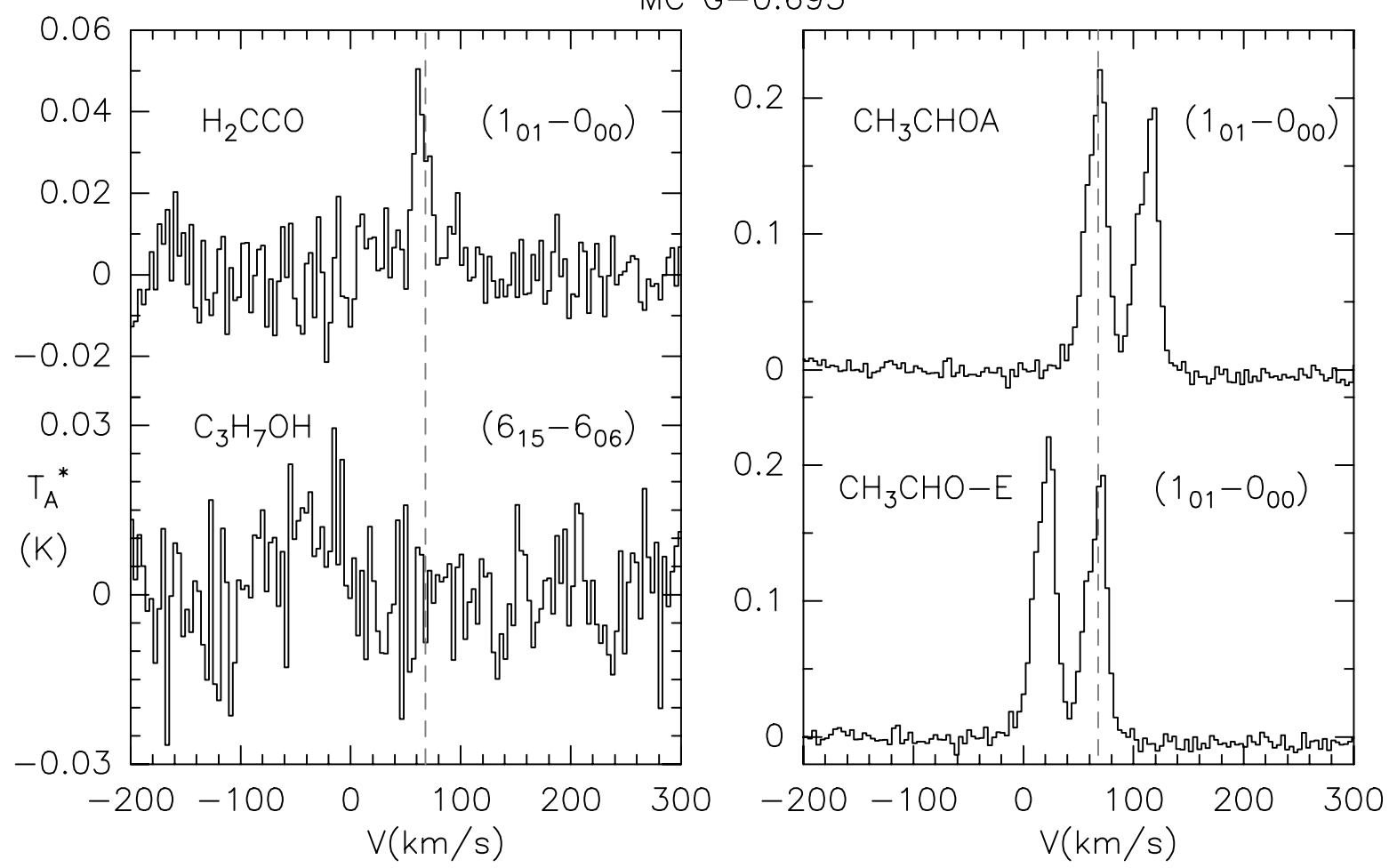

FIG. 2.-Spectra of the extra molecular transitions observed in MC G $+0.693-0.03$. This is the source with the most detections. [See the electronic edition of the Journal for a color version of this figure.]

TABLE 3

Gaussian Fit Parameters

\begin{tabular}{|c|c|c|c|c|c|c|c|c|c|c|}
\hline Molecule & TRansition & \multicolumn{3}{|c|}{ MC G-0.02 } & \multicolumn{3}{|c|}{ MC G-0.11 } & \multicolumn{3}{|c|}{$\mathrm{MC} \mathrm{G}+0.693$} \\
\hline $\mathrm{H}_{2} \mathrm{COH}^{+} \ldots \ldots \ldots \ldots \ldots \ldots$ & $2_{1,1} \rightarrow 2_{1,2}$ & $\ldots$ & $\ldots$ & $\ldots$ & $\ldots$ & $\ldots$ & $\ldots$ & $0.005(1)$ & 73(3) & $22(6)$ \\
\hline $\mathrm{CH}_{3} \mathrm{CH}_{2} \mathrm{CH}_{2} \mathrm{OH} \ldots \ldots \ldots \ldots$ & $6_{1,5} \rightarrow 6_{0,6}$ & $\ldots$ & $\ldots$ & $\ldots$ & $\ldots$ & $\ldots$ & $\ldots$ & $<0.024$ & $\ldots$ & $\ldots$ \\
\hline $\mathrm{CH}_{2} \mathrm{OHCHO} \ldots \ldots \ldots \ldots \ldots$ & $1_{1,0} \rightarrow 1_{0,1}$ & $0.010(1)$ & $52(1)$ & $23(3)$ & $0.009(1)$ & $22(1)$ & $21(3)$ & $0.023(1)$ & $69(1)$ & 24(1) \\
\hline $\mathrm{CH}_{2} \mathrm{OHCHO}$ & $2_{1,1} \rightarrow 2_{0,2}$ & $0.004(1)$ & $47(3)$ & $17(5)$ & $<0.006$ & & $\ldots$ & $0.013(1)$ & $69(1)$ & $15(2)$ \\
\hline $\mathrm{HOCH}_{2} \mathrm{CH}_{2} \mathrm{OH} \ldots \ldots \ldots \ldots$ & $3_{0,3}(0) \rightarrow 2_{0,2}(1)$ & $0.02(1)$ & $47(1)$ & $20(2)$ & $0.032(4)$ & $18(1)$ & $17(1)$ & $0.060(6)$ & $67(3)$ & $23(8)$ \\
\hline $\mathrm{HOCH}_{2} \mathrm{CH}_{2} \mathrm{OH} \ldots \ldots \ldots \ldots$ & $2_{0,2}(0) \rightarrow 1_{0,1}(1)$ & $0.008(1)$ & $50(2)$ & $15(4)$ & $0.013(1)$ & $18(1)$ & $14(2)$ & $0.020(1)$ & $59(1)$ & $24(2)$ \\
\hline $\mathrm{HC}_{2} \mathrm{CHO}$ & $2_{0,2} \rightarrow 1_{0,1}$ & $0.007(2)$ & $49(2)$ & $19(3)$ & $0.008(3)$ & $15(2)$ & $16(7)$ & $0.019(1)$ & $64(1)$ & $23(2)$ \\
\hline $\mathrm{HC}_{2} \mathrm{CHO}$ & $2_{1,1} \rightarrow 1_{1,0}$ & $\ldots$ & $\ldots$ & $\ldots$ & $\ldots$ & $\ldots$ & $\ldots$ & $0.005(1)$ & $70(3)$ & $21(10)$ \\
\hline $\mathrm{CH}_{2} \mathrm{CHCHO} \ldots \ldots \ldots \ldots \ldots$ & $2_{1,1} \rightarrow 1_{1,0}$ & $0.004(1)$ & $48(3)$ & $20(5)$ & $0.009(1)$ & 19(1) & 14(3) & $0.009(1)$ & $66(2)$ & $23(3)$ \\
\hline $\mathrm{CH}_{2} \mathrm{CHCHO} \ldots \ldots \ldots \ldots \ldots$ & $3_{1,3} \rightarrow 2_{1,2}$ & $<0.015$ & $\ldots$ & $\ldots$ & $0.010(2)$ & $20(1)$ & $17(3)$ & $0.013(5)$ & $67(2)$ & $15(3)$ \\
\hline $\mathrm{CH}_{3} \mathrm{OH}$ & $2_{2,3} \rightarrow 2_{1,3}$ & $0.373(1)$ & $46(1)$ & $21(1)$ & $0.226(1)$ & $18(1)$ & $16(1)$ & $0.543(3)$ & 69(1) & $20(1)$ \\
\hline $\mathrm{CH}_{3} \mathrm{OH} \ldots \ldots \ldots \ldots \ldots$ & $5_{2,3} \rightarrow 5_{1,3}$ & $0.176(6)$ & $45(1)$ & $21(1)$ & $0.097(6)$ & 19(1) & $16(7)$ & $0.19(2)$ & 69(1) & 21(1) \\
\hline $\mathrm{CH}_{3} \mathrm{OH} \ldots \ldots \ldots \ldots \ldots \ldots$ & $6_{2,3} \rightarrow 6_{1,3}$ & $0.118(6)$ & $45(1)$ & $22(1)$ & $0.060(4)$ & 19(1) & $15(1)$ & $0.101(8)$ & $70(1)$ & 24(1) \\
\hline $\mathrm{HCOOCH}_{3}-\mathrm{A} \ldots \ldots \ldots \ldots . . . .$. & $2_{1,1} \rightarrow 1_{1,0}$ & $0.020(6)$ & $49(2)$ & $27(6)$ & $0.021(2)$ & 19(1) & 19(1) & $0.042(5)$ & $65(1)$ & $25(2)$ \\
\hline $\mathrm{HCOOCH}_{3}-\mathrm{E} \ldots \ldots \ldots \ldots \ldots$ & $2_{1,1} \rightarrow 1_{1,0}$ & $0.018(6)$ & $46(2)$ & $23(5)$ & $0.022(2)$ & $17(1)$ & $17(1)$ & $0.041(5)$ & $67(1)$ & $22(2)$ \\
\hline 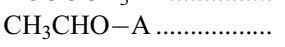 & $1_{0,1} \rightarrow 0_{0,0}$ & $\ldots$ & $\ldots$ & $\ldots$ & $\ldots$ & $\ldots$ & $\ldots$ & $0.21(2)$ & $67(1)$ & $23(1)$ \\
\hline $\mathrm{CH}_{3} \mathrm{CHO}-\mathrm{E} \ldots \ldots \ldots \ldots \ldots$ & $1_{0,1} \rightarrow 0_{0,0}$ & $\ldots$ & $\ldots$ & $\ldots$ & $\ldots$ & $\ldots$ & $\ldots$ & $0.18(2)$ & $67(1)$ & $22(1)$ \\
\hline $\mathrm{H}_{2} \mathrm{CCO} \ldots \ldots \ldots \ldots \ldots \ldots$ & $1_{0,1} \rightarrow 0_{0,0}$ & $\ldots$ & $\ldots$ & $\ldots$ & $\ldots$ & $\ldots$ & $\ldots$ & $0.043(6)$ & $64(1)$ & $17(3)$ \\
\hline $\mathrm{c}-\mathrm{C}_{2} \mathrm{H}_{4} \mathrm{O} \ldots \ldots \ldots \ldots \ldots$ & $2_{1,1} \rightarrow 2_{0,2}$ & $0.017(5)$ & $51(1)$ & $12(3)$ & $0.018(2)$ & $17(1)$ & $17(2)$ & $0.032(4)$ & $66(2)$ & $20(3)$ \\
\hline
\end{tabular}

NotE.-The intensities are shown in antenna temperature units (kelvins), and the upper limits correspond to $3 \sigma$. 

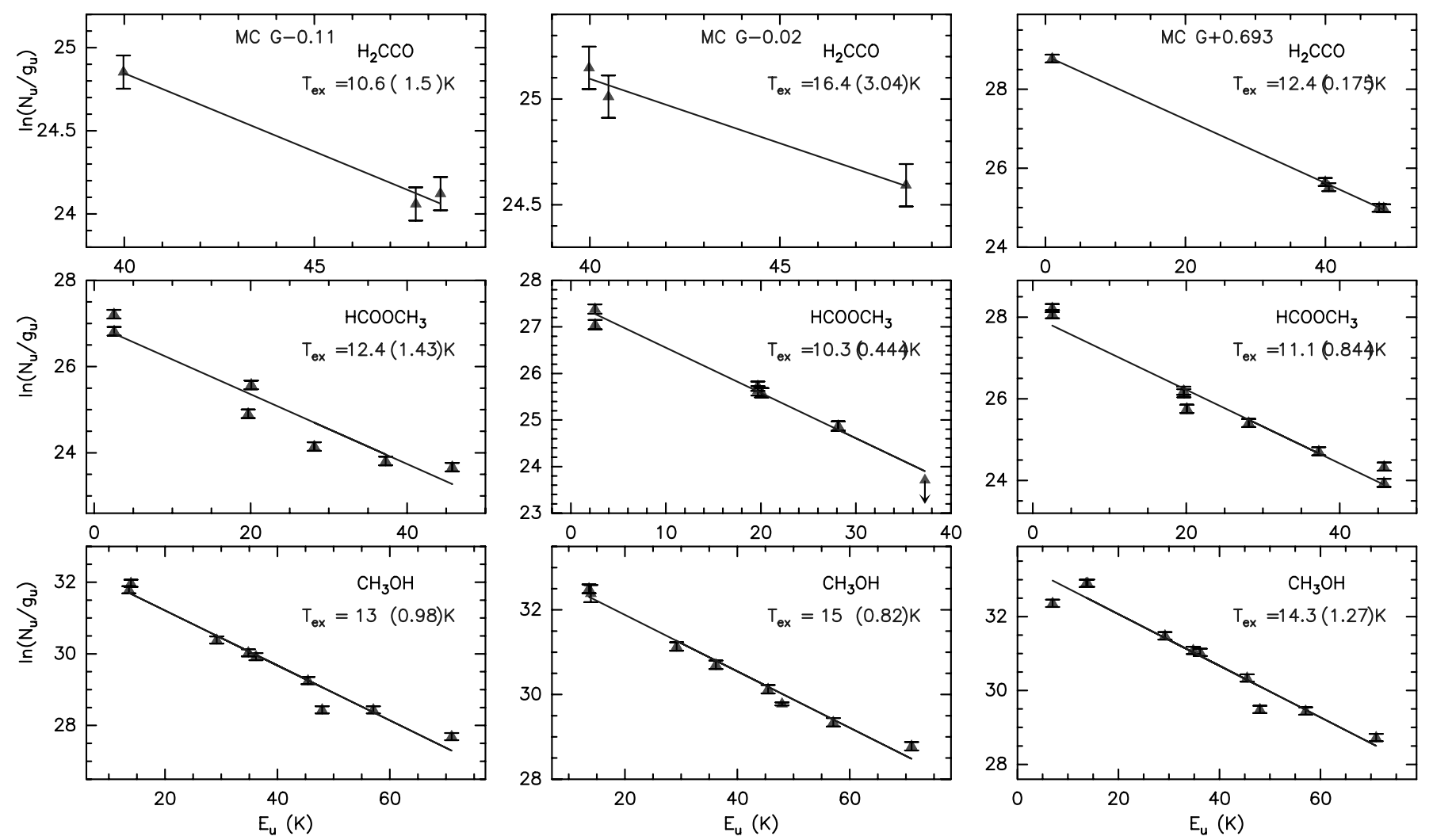

FIG. 3. - Population diagrams for $\mathrm{H}_{2} \mathrm{CCO}, \mathrm{HCOOCH}_{3}$, and $\mathrm{CH}_{3} \mathrm{OH}$ in the three observed sources. The population diagrams of $\mathrm{CH}_{3} \mathrm{OH}$ and $\mathrm{HCOOCH}_{3}$ also include data from Paper I. [See the electronic edition of the Journal for a color version of this figure.]

molecules (see Table 6), like the isomers and the aldehyde/alcohol pairs between the CMZ sources, the star-forming region Sgr B2N and a sample of hot cores in the Galactic disk (Bisschop et al. 2007).

\subsection{Isomers}

We find that the ratios between the different isomers in the $\mathrm{CMZ}$ sources are very similar within a factor of $\sim 3$. Only the $\left(\mathrm{CH}_{3}\right)_{2} \mathrm{O}: \mathrm{C}_{2} \mathrm{H}_{5} \mathrm{OH}$ ratio shows some dispersion between sources in the $\mathrm{CMZ}$. For the isomers $\mathrm{c}-\mathrm{C}_{2} \mathrm{H}_{4} \mathrm{O}: \mathrm{CH}_{3} \mathrm{CHO}$ ratio, the $\mathrm{CMZ}$

TABLE 4

Abundance Ratios with Respect to $\mathrm{H}_{2}$

\begin{tabular}{|c|c|c|c|}
\hline Molecule & $\mathrm{MC} \mathrm{G}-0.02$ & $\mathrm{MC} \mathrm{G}-0.11$ & $\mathrm{MC} \mathrm{G}+0.693$ \\
\hline $\mathrm{HC}_{2} \mathrm{CHO} \ldots \ldots \ldots \ldots \ldots \ldots$ & $0.5 \mathrm{E}-9$ & $2.3 \mathrm{E}-9$ & $1.6 \mathrm{E}-9$ \\
\hline $\mathrm{CH}_{2} \mathrm{CHCHO} \ldots \ldots \ldots \ldots \ldots \ldots$ & $0.3 \mathrm{E}-9$ & $2.3 \mathrm{E}-9$ & $0.9 \mathrm{E}-9$ \\
\hline $\mathrm{CH}_{3} \mathrm{CH}_{2} \mathrm{CHO} \ldots \ldots \ldots \ldots \ldots \ldots \ldots$ & $1.4 \mathrm{E}-9$ & $4.4 \mathrm{E}-9$ & $3.9 \mathrm{E}-9$ \\
\hline $\mathrm{CH}_{2} \mathrm{OHCHO}$ & $0.3 \mathrm{E}-8$ & $1.8 \mathrm{E}-8$ & $0.9 \mathrm{E}-8$ \\
\hline $\mathrm{HOCH}_{2} \mathrm{CH}_{2} \mathrm{OH} \ldots \ldots \ldots \ldots \ldots \ldots$ & $0.4 \mathrm{E}-8$ & $2.8 \mathrm{E}-8$ & $1.1 \mathrm{E}-8$ \\
\hline $\mathrm{HCOOCH}_{3} \ldots \ldots \ldots \ldots \ldots \ldots \ldots \ldots \ldots \ldots \ldots$ & $1.0 \mathrm{E}-8$ & $7.8 \mathrm{E}-8$ & $4.7 \mathrm{E}-8$ \\
\hline $\mathrm{c}-\mathrm{C}_{2} \mathrm{H}_{4} \mathrm{O}$ & $1.1 \mathrm{E}-9$ & $5.6 \mathrm{E}-9$ & $3.0 \mathrm{E}-9$ \\
\hline $\mathrm{CH}_{3} \mathrm{CHO}^{*} \ldots \ldots \ldots \ldots \ldots \ldots$ & $1.0 \mathrm{E}-8$ & $3.0 \mathrm{E}-8$ & $3.6 \mathrm{E}-8$ \\
\hline $\mathrm{H}_{2} \mathrm{CCO}^{*} \ldots \ldots \ldots \ldots \ldots \ldots \ldots \ldots$ & $0.2 \mathrm{E}-8$ & $1.6 \mathrm{E}-8$ & $0.7 \mathrm{E}-8$ \\
\hline $\mathrm{H}_{2} \mathrm{CO}^{*}$ & $1.6 \mathrm{E}-8$ & $6.5 \mathrm{E}-8$ & $0.9 \mathrm{E}-8$ \\
\hline $\mathrm{H}_{2} \mathrm{COH}^{+*}$ & $<1.1 \mathrm{E}-9$ & $<1.3 \mathrm{E}-9$ & $2.4 \mathrm{E}-9$ \\
\hline $\mathrm{CH}_{3} \mathrm{OH} \ldots \ldots \ldots \ldots \ldots \ldots \ldots \ldots \ldots \ldots \ldots \ldots \ldots \ldots \ldots$ & $0.3 \mathrm{E}-6$ & $1.1 \mathrm{E}-6$ & $0.5 \mathrm{E}-6$ \\
\hline
\end{tabular}

Notes.-Relative abundances with respect to that of $\mathrm{H}_{2}$. The $\mathrm{H}_{2}$ column densities used to estimate the abundances are $6.8 \times 10^{22} \mathrm{~cm}^{-2}$ for MC G-0.02-0.07, $1 \times 10^{22} \mathrm{~cm}^{-2}$ for MC G-0.11-0.08, and 4.1 $\times 10^{22} \mathrm{~cm}^{-2}$ for $\mathrm{MC} \mathrm{G}+0.693-0.03$, from Paper I. For the molecules marked with an asterisk $\left(^{*}\right)$, we have used data from Martín (2006). sources show ratios that are in agreement with those measured in hot cores (Nummelin et al. 1998; Bennett et al. 2005). However, for the $\left(\mathrm{CH}_{3}\right)_{2} \mathrm{O}: \mathrm{C}_{2} \mathrm{H}_{5} \mathrm{OH}$ ratio, we find a large difference between the $\mathrm{GC}$ clouds and the hot core sources by nearly a factor of 10. The ratios $\mathrm{CH}_{3} \mathrm{COOH}: \mathrm{CH}_{2} \mathrm{OHCHO}: \mathrm{HCOOCH}_{3}$, where we have only upper limits for the $\mathrm{CH}_{3} \mathrm{COOH}$ abundance, is relatively constant for the $\mathrm{CMZ}$ sources, but the abundance of $\mathrm{CH}_{2} \mathrm{OHCHO}$ with respect to that of $\mathrm{HCOOCH}_{3}$ is larger in the $\mathrm{CMZ}$ than in hot cores by a factor of 10 . The trend observed in the relative abundances between isomers indicates a similar grain mantle composition in the CMZ, but different than in hot core regions. The new detections of COMs clearly show that the

TABLE 5

Abundance Ratios with Respect to $\mathrm{CH}_{3} \mathrm{OH}$

\begin{tabular}{|c|c|c|c|}
\hline Molecule & $\mathrm{MC} \mathrm{G}-0.02$ & $\mathrm{MC} \mathrm{G}-0.11$ & $\mathrm{MC} \mathrm{G}+0.693$ \\
\hline $\mathrm{HC}_{2} \mathrm{CHO}$ & $1.6 \mathrm{E}-3$ & $2.1 \mathrm{E}-3$ & $3.6 \mathrm{E}-3$ \\
\hline $\mathrm{CH}_{2} \mathrm{CHCHO} \ldots \ldots \ldots \ldots \ldots \ldots$ & $9.1 \mathrm{E}-4$ & $2.1 \mathrm{E}-3$ & $2.0 \mathrm{E}-3$ \\
\hline $\mathrm{CH}_{3} \mathrm{CH}_{2} \mathrm{CHO} \ldots \ldots \ldots \ldots \ldots \ldots$ & $3.9 \mathrm{E}-3$ & $<4.0 \mathrm{E}-3$ & $8.7 \mathrm{E}-3$ \\
\hline $\mathrm{CH}_{2} \mathrm{OHCHO}$ & $1.0 \mathrm{E}-2$ & $1.5 \mathrm{E}-2$ & $2.0 \mathrm{E}-2$ \\
\hline $\mathrm{HOCH}_{2} \mathrm{CH}_{2} \mathrm{OH} \ldots \ldots \ldots \ldots \ldots$ & $1.2 \mathrm{E}-2$ & $2.0 \mathrm{E}-2$ & $2.4 \mathrm{E}-2$ \\
\hline $\mathrm{HCOOCH}_{3} \ldots \ldots \ldots \ldots \ldots \ldots \ldots$ & $3.4 \mathrm{E}-2$ & $7.1 \mathrm{E}-2$ & $1.0 \mathrm{E}-1$ \\
\hline $\mathrm{c}-\mathrm{C}_{2} \mathrm{H}_{4} \mathrm{O} \ldots \ldots \ldots \ldots \ldots \ldots \ldots \ldots \ldots \ldots \ldots \ldots \ldots$ & $3.7 \mathrm{E}-3$ & $5.1 \mathrm{E}-3$ & $6.7 \mathrm{E}-3$ \\
\hline $\mathrm{CH}_{3} \mathrm{CHO}^{*} \ldots \ldots \ldots \ldots \ldots \ldots$ & $3.5 \mathrm{E}-2$ & $2.7 \mathrm{E}-2$ & $5.7 \mathrm{E}-2$ \\
\hline $\mathrm{H}_{2} \mathrm{CCO}^{*} \ldots \ldots \ldots \ldots \ldots \ldots \ldots$ & $6.4 \mathrm{E}-3$ & $1.5 \mathrm{E}-2$ & $1.6 \mathrm{E}-2$ \\
\hline 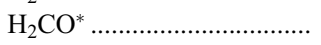 & $5.3 \mathrm{E}-2$ & $5.9 \mathrm{E}-2$ & $2.0 \mathrm{E}-2$ \\
\hline $\mathrm{H}_{2} \mathrm{COH}^{+*}$ & $<3.8 \mathrm{E}-3$ & $<1.2 \mathrm{E}-3$ & $5.3 \mathrm{E}-3$ \\
\hline 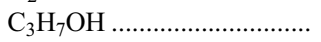 & $\ldots$ & $\ldots$ & $\leq 1.6 \mathrm{E}-2$ \\
\hline
\end{tabular}

NoTES.-Relative abundances of the different molecules with respect to that of $\mathrm{CH}_{3} \mathrm{OH}$. For the molecules marked with an asterisk $\left(^{*}\right)$, we have used data from Martín (2006). 


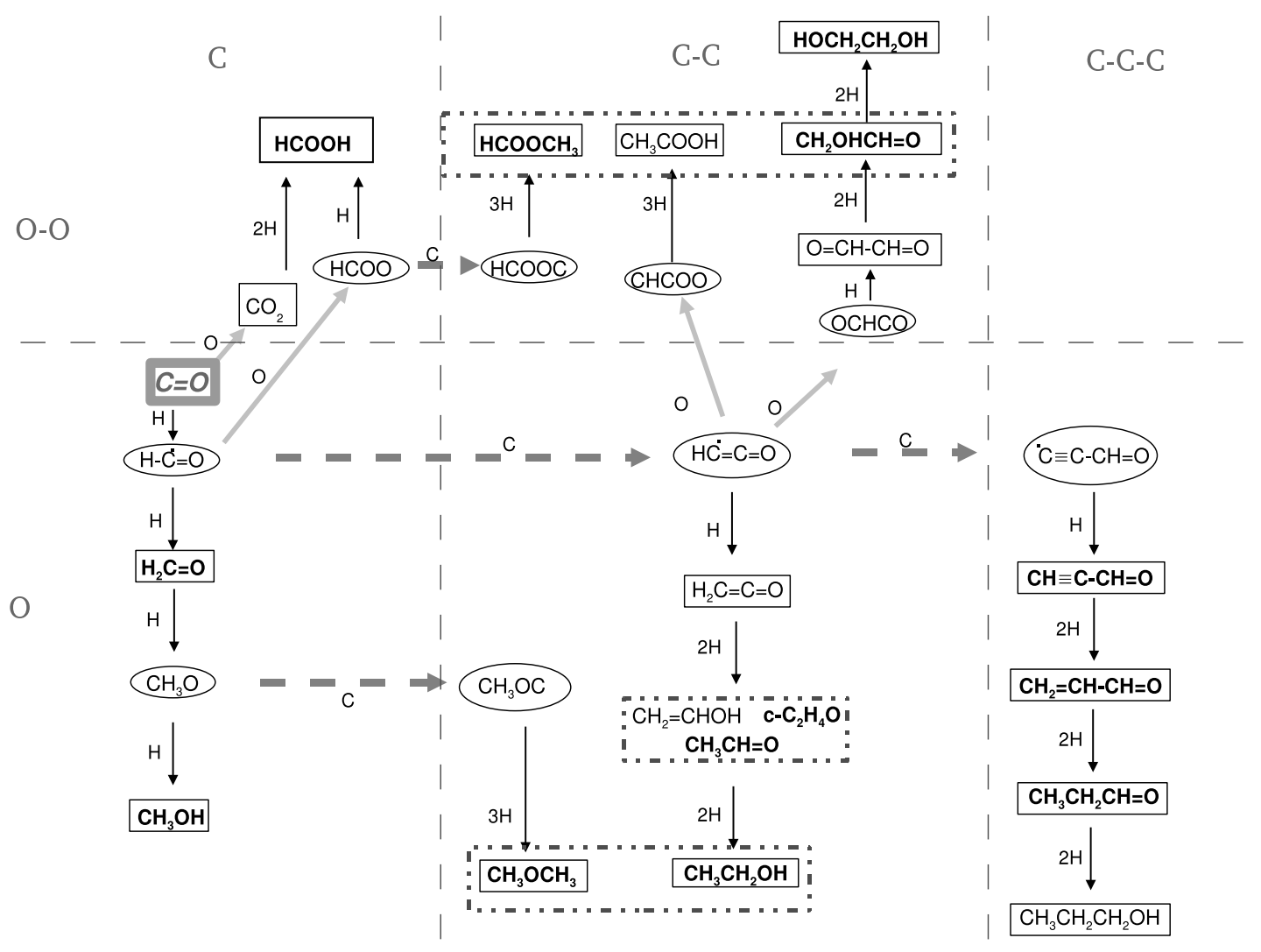

FIG. 4.-Proposed scheme for the formation of COMs on interstellar grain surfaces by addition of $\mathrm{C}, \mathrm{O}$, and $\mathrm{H}$ on the grain mantles. Complexity increases from left to right by adding $\mathrm{C}$ (three areas $\mathrm{C}, \mathrm{C}-\mathrm{C}$, and $\mathrm{C}-\mathrm{C}-\mathrm{C}$ separated by dashed lines), from center to bottom and to top by adding $\mathrm{H}$, and in diagonal by adding $\mathrm{O}$ (two areas $\mathrm{O}$ and $\mathrm{O}-\mathrm{O}$ separated by dashed lines). Radicals are encapsulated in ellipses, and the other molecular species are in boxes. The molecules in boldface have been already detected in the GC clouds we studied. The other molecules have been not detected or their spectroscopic parameters for their search are unknown. The thin dashed boxes separate the families of isomers. Adapted from Charnley \& Rodgers (2005) and Tielens \& Hagen (1982).

TABLE 6

Relative Abundances between Related Molecules

\begin{tabular}{|c|c|c|c|c|}
\hline Molecular Ratios & MC G-0.02 & MC G-0.11 & $\mathrm{MC} \mathrm{G}+0.693$ & Hot Cores \\
\hline \multicolumn{5}{|c|}{ Isomers } \\
\hline $\mathrm{c}-\mathrm{C}_{2} \mathrm{H}_{4} \mathrm{O}: \mathrm{CH}_{3} \mathrm{CHO}$ & $0.1: 1$ & $0.2: 1$ & $0.1: 1$ & $0.08-0.2: 1$ \\
\hline$\left(\mathrm{CH}_{3}\right)_{2} \mathrm{O}^{1}: \mathrm{C}_{2} \mathrm{H}_{5} \mathrm{OH}^{\mathrm{a}}$ & $1.3: 1$ & $0.9: 1$ & $0.4: 1$ & $3.2: 1$ \\
\hline $\mathrm{CH}_{3} \mathrm{COOH}^{1}: \mathrm{CH}_{2} \mathrm{OHCHO}: \mathrm{HCOOCH}_{3} \ldots \ldots \ldots \ldots . . . .$. & $<0.05: 0.3: 1$ & $<0.05: 0.2: 1$ & $<0.04: 0.2: 1$ & $\sim 0.04: 0.02: 1$ \\
\hline \multicolumn{5}{|c|}{ Aldehyde/Alcohol } \\
\hline $\mathrm{H}_{2} \mathrm{CO}: \mathrm{CH}_{3} \mathrm{OH}$ & $0.05: 1$ & $0.06: 1$ & $0.02: 1$ & $0.2: 1^{\mathrm{b}}$ \\
\hline $\mathrm{CH}_{3} \mathrm{CHO}: \mathrm{C}_{2} \mathrm{H}_{5} \mathrm{OH}$ & $0.9: 1$ & $0.5: 1$ & $0.8: 1$ & $1.5 \mathrm{E}-3: 1^{\mathrm{b}}$ \\
\hline $\mathrm{CH}_{3} \mathrm{CH}_{2} \mathrm{CHO}: \mathrm{C}_{3} \mathrm{H}_{7} \mathrm{OH}$ & $\ldots$ & $\ldots$ & $>0.5: 1$ & $\ldots$ \\
\hline $\mathrm{CH}_{2} \mathrm{OHCHO}: \mathrm{HOCH}_{2} \mathrm{CH}_{2} \mathrm{OH} \ldots \ldots \ldots \ldots \ldots \ldots \ldots \ldots$ & $0.8: 1$ & $0.8: 1$ & $0.8: 1$ & $0.5-1.4: 1$ \\
\hline \multicolumn{5}{|c|}{ Hydrogenation } \\
\hline $\mathrm{H}_{2} \mathrm{CCO}: \mathrm{CH}_{3} \mathrm{CHO}$ & $1: 5.6$ & $1: 1.8$ & $1: 3.6$ & $1: 0.2^{\mathrm{b}}$ \\
\hline $\mathrm{HC}_{2} \mathrm{CHO}: \mathrm{CH}_{2} \mathrm{CHCHO}: \mathrm{CH}_{3} \mathrm{CH}_{2} \mathrm{CHO} \ldots \ldots \ldots \ldots$ & $1: 0.6: 2.4$ & $1: 1.0:<1.9$ & $1: 0.6: 2.4$ & $1: 0.8: 4.7$ \\
\hline $\mathrm{H}_{2} \mathrm{CO}: \mathrm{H}_{2} \mathrm{COH}^{+}: \mathrm{CH}_{2} \mathrm{OHCHO}$ & $1:<0.07: 0.2$ & $1:<0.02: 0.3$ & $1: 0.3: 1$ & $1: \sim 0.1: 0.03$ \\
\hline
\end{tabular}

Note.-The values of the Sgr B2N hot core are obtained from Hollis et al. $(2001,2002,2004 b)$, Nummelin et al. (1998), Halfen et al. (2006), and Ohishi et al. (1996).

${ }^{a}$ CMZ values from Paper I.

${ }^{b}$ Values are from Bisschop et al. (2007) and are the averaged values of some hot cores (in their work the $\mathrm{CH}_{3} \mathrm{CHO}$ and $\mathrm{H}_{2} \mathrm{CCO}$ lie in a cooler gas than the $\mathrm{C}_{2} \mathrm{H}_{5} \mathrm{OH}$ ) and the rest of the COMs. 
chemistry in the CMZ differs substantially from that in hot cores in the Galactic disk.

\subsection{Aldehyde/Alcohol Pair}

Previous observations of the aldehyde/alcohol pairs in hot cores have shown that the COM chemistry favors the reduced alcohols with respect to their corresponding aldehydes (Ikeda et al. 2001; Hollis et al. 2002; Bisschop et al. 2007), i.e., the double bond between the $\mathrm{C}$ and the $\mathrm{O}$ must be easily broken. In the CMZ we found a similar trend (Table 6). However, when we compare the hot cores with the CMZ clouds we find very large differences between their relative abundances. For the $\mathrm{H}_{2} \mathrm{CO}$ : $\mathrm{CH}_{3} \mathrm{OH}$ and the $\mathrm{CH}_{2} \mathrm{OHCHO}: \mathrm{HOCH}_{2} \mathrm{CH}_{2} \mathrm{OH}$ pairs we find small differences and it could be explained by slightly different grain mantle composition between $\mathrm{CMZ}$ sources and hot cores. However, for the $\mathrm{CH}_{3} \mathrm{CHO}: \mathrm{C}_{2} \mathrm{H}_{5} \mathrm{OH}$ pair, the ratio in the $\mathrm{CMZ}$ is more than 2 orders of magnitude larger than in hot cores. This might be attributable to the suggestion that the $\mathrm{CH}_{3} \mathrm{CHO}$ formation in hot cores may be related with a cooler gas in the external part of the hot core (Bisschop et al. 2007).

\subsection{Degree of Saturation}

Finally, we compare the abundances between molecules related by a different degree of saturation, breaking double or triple bonds (columns in Fig. 4). For the pair $\mathrm{H}_{2} \mathrm{CCO}: \mathrm{CH}_{3} \mathrm{CHO}$ the relative abundances observed in the $\mathrm{CMZ}$ are completely different than observed in hot cores. The relative $\mathrm{CH}_{3} \mathrm{CHO}$ abundance with respect to that of $\mathrm{H}_{2} \mathrm{CCO}$ is larger by more that 1 order of magnitude in the $\mathrm{CMZ}$ clouds than that observed by Bisschop et al. (2007) in hot cores. The break of the double bond seems to be produced more efficiently in the CMZ, maybe because of a more efficient hydrogenation.

For the aldehydes bearing three carbons, we found similar ratios between $\mathrm{CMZ}$ sources. Unfortunately, these aldehydes have only been detected toward one hot core, Sgr B2N. Moreover, we derive similar abundance ratios in the Sgr B2N hot core than in the other CMZ clouds for these molecules, assuming a low-excitation temperature (10 K; Hollis et al. 2004b). Their extended emission in the CMZ is a clear indication that these molecules might not arise from the hot core, but from the envelope (Martín-Pintado et al. 1990). Detection of these molecules in other hot cores is required to establish whether the addition of carbon also occurs with the same efficiency in hot cores as in the CMZ.

\section{THE FORMATION OF COMs}

The formation paths for the observed COMs are not completely understood, either in the gas phase or on grain mantles (Charnley \& Rodgers 2005; Halfen et al. 2006). From the observational point of view, up to now, our knowledge of the most complex organic molecules has been restricted to just one position toward a hot core, Sgr B2N, with several velocity components that complicate its study. The detection of very similar abundances of large COMs in several different zones in the CMZ opens the possibility of constraining the formation mechanism for the most complex molecules found in the interstellar medium.

\subsection{Gas Phase}

The very high abundances obtained for the COMs and again the similar abundance ratios between the different COMs with respect to that of $\mathrm{CH}_{3} \mathrm{OH}$ strongly supports the hypothesis that the same chemistry occurs at different locations in the CMZ. Gasphase reactions of simple organic molecules ejected from grain mantles to form the more complex organic molecules (as pro- posed by Charnley et al. 1992) are unlikely to produce the same uniform abundance ratios, because the abundances of the daughter species are strongly time dependent and also dependent on the temperature and density.

The detection of $\mathrm{H}_{2} \mathrm{COH}^{+}$toward the Sgr B2N hot core has been proposed as an indication of the gas-phase formation of $\mathrm{CH}_{2} \mathrm{OHCHO}$ (Halfen et al. 2006). However, in the CMZ the abundance of $\mathrm{H}_{2} \mathrm{COH}^{+}$seems to be very low as compared with that of $\mathrm{CH}_{2} \mathrm{OHCHO}$ (Table 6) to explain the formation of this molecule in the gas phase. The most likely explanation is that $\mathrm{CH}_{2} \mathrm{OHCHO}$, like the other COMs, is formed on grain mantles.

We stress that the GC molecular clouds are likely to be more affected by different energetic processes, UV radiation, X-rays, supernova remnants, shocks, and cosmic rays than the clouds in the Galactic disk. These effects can drive the chemistry in grain mantles and/or increase the available $\mathrm{H}$ in the gas phase or in icy grain mantles, making a larger degree of hydrogenation in the $\mathrm{CMZ}$ possible. Fast hydrogenation reactions in the gas phase after the ejection of COMs from the mantles could also be possible, but should affect differently the different clouds. In particular, such a situation should be time dependent, since the degree of hydrogenation will depend on the timescales when the parent COMs were ejected from the grain mantles. As discussed in Paper I, we do not find any change in the relative abundances of fully saturated molecules like $\mathrm{C}_{2} \mathrm{H}_{5} \mathrm{OH}$, suggesting that gas-phase chemistry after the ejection of molecules from grain mantles does not seem to be a fundamental process.

\subsection{Icy Mantles of Grains}

The constant relative abundances and abundance ratios of the more complex organic molecules observed in the $\mathrm{CMZ}$ indicate that the chemistry of all these molecules is likely to be related with common processes taking place throughout the CMZ. The formation of those complex molecules by hydrogenation of $\mathrm{CO}$ to form $\mathrm{H}_{2} \mathrm{CO}$ and $\mathrm{CH}_{3} \mathrm{OH}$ on grain mantles seems to be very efficient in laboratory experiments (Hiraoka et al. 2002; Watanabe 2005; Fuchs 2007). Similar hydrogenation reactions might then be possible for the formation of more complex molecules by addition of $\mathrm{O}$ and $\mathrm{C}$ (see Fig. 4). In fact, one of the largest COMs, $\mathrm{HOCH}_{2} \mathrm{CH}_{2} \mathrm{OH}$, has even been detected in comets by Crovisier et al. (2004).

In the scheme proposed in Figure 4, chemical complexity follows from the availability of atomic $\mathrm{C}, \mathrm{H}$, and $\mathrm{O}$ in the gas phase. The $\mathrm{C}$ availability results from cosmic-ray ionization and primary and secondary electron excitation of $\mathrm{H}_{2}$ followed by fluorescence in the Lyman-Werner bands that produce far-ultraviolet (FUV) photons capable of photodissociating $\mathrm{CO}$. The fractional $\mathrm{C}$ abundance is $\mathrm{C} / \mathrm{CO} \sim 6 \times 10^{-3}$, largely independent of the cosmic-ray ionization rate, and therefore, the carbon addition must be similar in the different regions (Tielens 2005). Other formation routes from various simple molecules, including hydrocarbons such as acetylene $\left(\mathrm{C}_{2} \mathrm{H}_{2}\right)$, where its triple bond is readily attacked by atomic $\mathrm{H}$, could also lead to $\mathrm{COMs}$ such as $\mathrm{CH}_{2} \mathrm{CHOH}$ as well as $\mathrm{C}_{2} \mathrm{H}_{5} \mathrm{OH}$.

Another attractive alternative for the formation of the largest COMs on grains is that energetic processes in the GC fragment the simple molecules formed by hydrogenation of $\mathrm{CO}$, like $\mathrm{H}_{2} \mathrm{CO}$ and $\mathrm{CH}_{3} \mathrm{OH}$, triggering further hydrogenation and other reactions on grain surfaces. Following this hypothesis for the formation of COMs, the reactions of radicals at warm dust temperatures (Garrod \& Herbst 2006) seems to be important, but the present chemical models do not show any result for the complex aldehydes we have observed in this work and the dust temperatures in the CMZ are relatively low, only $10-20 \mathrm{~K}$. Several COMs, 
such as the simpler amino acids, can be formed in the solid phase from $\mathrm{H}_{2} \mathrm{O}, \mathrm{CH}_{3} \mathrm{OH}, \mathrm{NH}_{3}$, and $\mathrm{CO}$ or $\mathrm{HCN}$ ices affected by photochemistry (Dworkin et al. 2001; Bernstein et al. 2002). However, most of the COMs are easily photodissociated by the UV radiation needed to drive the chemistry (see Paper I).

A very interesting alternative has been investigated by Bennett \& Kaiser (2007), who have irradiated a mixture of $\mathrm{CH}_{3} \mathrm{OH}$ and $\mathrm{CO}$ ices at $10 \mathrm{~K}$ with energetic electrons to mimic the effects of $\mathrm{MeV}$ cosmic rays. As previously mentioned, $\mathrm{GC}$ clouds could be affected by an enhanced flux of cosmic rays. Cosmic rays break a $\mathrm{C}-\mathrm{H}$ bond of $\mathrm{CH}_{3} \mathrm{OH}$, generating the hydroxymethyl $\left(\mathrm{CH}_{2} \mathrm{OH}\right)$ and the metoxy $\left(\mathrm{CH}_{3} \mathrm{O}\right)$ radicals, plus $\mathrm{H}$. This $\mathrm{H}$ has sufficient energy to overcome barriers on the grain mantles to hydrogenate $\mathrm{CO}$ to form $\mathrm{HCO}$. This radical will recombine with $\mathrm{CH}_{2} \mathrm{OH}$ to form $\mathrm{CH}_{2} \mathrm{OHCHO}$ and with $\mathrm{CH}_{3} \mathrm{O}$ to form $\mathrm{HCOOCH}_{3}$. In this scheme, the isomers, $\mathrm{CH}_{2} \mathrm{OHCHO}$ and $\mathrm{HCOOCH}_{3}$, are efficiently formed while their other isomer $\mathrm{CH}_{3} \mathrm{COOH}$ was produced with less efficiency than the other two. The same trend predicted by this experiment in the abundances of these isomers is observed in the $\mathrm{GC}$ clouds. Furthermore, $\mathrm{HCOOCH}_{3}$ is formed more efficiently than $\mathrm{CH}_{2} \mathrm{OHCHO}$ by 1 order of magnitude, just as we observed in the GC clouds. This suggests than cosmic rays can be the driver of grain chemistry in the GC. However, it is unclear if the estimated abundances of the $\mathrm{C}_{2} \mathrm{H}_{4} \mathrm{O}_{2}$ species on the ices of $1 \%$ of water abundances (Bennett \& Kaiser 2007) are large enough to account for the abundances estimated from our observation. This would require that the $\mathrm{CH}_{3} \mathrm{OH}$ abundance in the mantles be similar to that of water in the GC.

All these arguments emphasize the suggestion made in Paper I that we observe in the $\mathrm{CMZ}$ a uniform grain mantle composition ejected directly from the grain mantles to the gas phase. However, the grain chemistry in the CMZ differs substantially from that in hot cores.

\section{POTENTIAL OF THE CMZ FOR FUTURE SEARCHES OF COMs}

Because of the large number of detections of COMs in the $\mathrm{CMZ}$, as well as their large abundances, this region stands out as one of the most promising sources for detecting new molecules and for studying the origin of COMs in the Galaxy. In hot cores, the other prolific sources of COMs, line confusion and large partition functions make the detection/identification of very large molecules very difficult. In the CMZ, the COMs are widespread and show low-excitation temperatures $(\$ 20 \mathrm{~K})$, partially avoiding the large partition function and the extreme line confusion problems of the hot cores. Moreover, there are molecules like the complex aldehydes which are more abundant in the CMZ clouds affected by shocks than in hot cores. Observations of these mol- ecules in a larger sample of CMZ clouds and hot cores, and new studies of the chemistry for the large aldehydes are necessary to clearly establish the different history of the grain mantles in the $\mathrm{GC}$ and in the disk.

\section{CONCLUSIONS}

We have detected the most complex organic molecules, $\mathrm{HC}_{2} \mathrm{CHO}$, $\mathrm{CH}_{2} \mathrm{CHCHO}, \mathrm{CH}_{3} \mathrm{CH}_{2} \mathrm{CHO}, \mathrm{CH}_{2} \mathrm{OHCHO}, \mathrm{HOCH}_{2} \mathrm{CH}_{2} \mathrm{OH}$, c- $\mathrm{C}_{2} \mathrm{H}_{4} \mathrm{O}, \mathrm{CH}_{3} \mathrm{CHO}$, and HCCCHO, in three typical GC molecular clouds. These molecules show very high abundances relative to $\mathrm{H}_{2}$, ranging from $10^{-10}$ to $10^{-8}$. The relative abundances of the different molecules with respect to that of $\mathrm{CH}_{3} \mathrm{OH}$ are very similar within a factor of 3 for the three sources in the CMZ and likely everywhere in this region, as previously observed for a larger sample of sources for other related COMs (Paper I). The new data strengthen our previous claim of a uniform grain mantle composition and similar chemical histories of the grain mantles in the CMZ clouds. However, comparison between the CMZ clouds and hot cores shows very large differences in the relative abundances of some of the molecules presented in this paper, indicating a different grain mantle composition in the Galactic disk hot cores possibly due to a different chemical history. Hydrogenation and carbon addition seem to be more efficient in the GC than in the hot cores of the Galactic disk. The GC is the most extreme environment in the Galaxy with the presence of energetic processes, like UV radiation, X-rays, and cosmic rays. These will affect the chemistry on the grain mantles in the CMZ and/or increase the $\mathrm{H}$ and $\mathrm{C}$ abundances in the gas phase available for fast hydrogenation and carbon addition of unsaturated molecules on grain mantles. Other hypotheses, like the formation from radicals driven by cosmic rays, seem also to be very promising. The $\mathrm{CMZ}$ is one of the most promising sources to increment our knowledge of the chemical complexity in the interstellar medium.

We thank A. G. G. M. Tielens for his comments on Figure 4 and for a discussion of the formation of COMs on grain mantles that contributed substantially to the improvement of the final version of the manuscript. This work has been supported by the Spanish Ministerio de Educación y Ciencia under projects AYA 2003-02785, ESP 2004-00665, ESP 2007-65812-C02-01 and "Comunidad de Madrid" Government under PRICIT project S0505/ESP-0237 (ASTROCAM). The participation of M. Morris in this project was supported by NSF award INT-0340750 to UCLA.

Facilities: GBT
Bally, J., Stark, A. A., Wilson, R. W., \& Henkel, C. 1987, ApJS, 65, 13 Bennett, C. J., \& Kaiser, R. I. 2007, ApJ, 661, 899

Bennett, C. J., Osamura, Y., Lebar, M. D., \& Kaiser, R. I. 2005, ApJ, 634, 698 Bernstein, A., Dworkin, A., Sandford, A., Cooper, A., \& Allamandola, A. 2002, Nature, 416, 401

Bisschop, S. E., Jørgensen, J. K., van Dishoeck, E. F., \& de Wachter, E. B. 2007, A\&A, 465, 913

Charnley, S. B., \& Rodgers, S. D. 2005, in IAU Symp. 231, Astrochemistry: Recent Successes and Future Challenges, ed. D. C. Lis, G. A. Blake, \& E. Herbst (Cambridge: Cambridge Univ. Press), 237

Charnley, S. B., Tielens, A. G. G. M., \& Millar, T. J. 1992, ApJ, 399, L71

Chengalur, J. N., \& Kanekar, N. 2003, A\&A, 403, L43

Crovisier, J., Bockele-Morvan, D., Biver, N., Colom, P., Despois, D., \& Lis, D. C. 2004, A\&A, 418, L35

Dickens, J. E., et al. 2001, Spectrochim. Acta A, 57, 643

\section{REFERENCES}

Dworkin, A., Deamer, A., Sandford, A., \& Allamandola, A. 2001, Proc. Natl. Acad. Sci., 98, 815

Fuchs, G. W., Ioppolo, S., Bisschop, S. E., Van Dishoeck, E. F., \& Linnartz, H. 2007, A\&A, submitted

Garrod, R. T., \& Herbst, E. 2006, A\&A, 457, 927

Greenberg, J. M. 1976, Ap\&SS, 39, 9

Halfen, D. T., Apponi, A. J., Woolf, N., Polt, R., \& Ziurys, L. M. 2006, ApJ, 639,237

Hiraoka, K., Sato, T., Sato, S., Sogoshi, N., Yokoyama, T., Takashima, H., \& Kitagawa, S. 2002, ApJ, 577, 265

Hollis, J. M., Lovas, F. J., \& Jewell, P. R. 2000, ApJ, 540, L107

Hollis, J. M., Lovas, F. J., Jewell, P. R., \& Courdert, L. H. 2002, ApJ, 571, L59

Hollis, J. M., Jewell, P. R., Lovas, F. J., \& Remijan, A. 2004, ApJ, 613, L45

Hollis, J. M., Jewell, P. R., Lovas, F. J., Remijan, A., \& Møllendal, H. 2004 ApJ, 610, L21 
Hollis, J. M., Vogel, S. N., Snyder, L. E. Jewell, P. R., \& Lovas, F. J. 2001, ApJ, $554, \mathrm{~L} 81$

Hüttemeister, S. 1993, Ph.D. thesis, Bonn Univ.

Hüttemeister, S., Dahmen, G., Mauesberger, R., Henkel, C., Wilson, T. L., \& Martín-Pintado, J. 1998, A\&A, 334, 646

Ikeda, M., et al. 2001, ApJ, 560, 792

Jamieson, C. S., Mebel, A. M., \& Kaiser, R. I. 2006, ApJS, 163, 184

Jiménez-Serra, I., Caselli, P., Martín-Pintado, J., \& Hartquist, T. W. 2007, A\&A, submitted

Martín, S. 2006, Ph.D. thesis, Univ. Complutense

Martín-Pintado, J., de Vicente, P., Fuente, A., \& Planesas, P. 1997, ApJ, 482, L45

Martín-Pintado, J., de Vicente, P., Wilson, T. L., \& Johnston, K. J. 1990, A\&A, 236, 193

Martín-Pintado, J., Rizzo, J. R., de Vicente, P., Rodríguez-Fernández, N. J., \& Fuente, A. 2001, ApJ, 548, L65

Morris, M., \& Serabyn, E. 1996, ARA\&A, 34, 645

Müller, H. S. P., Schlöder, F., Stutzki, J., \& Winnewisser, G. 2005, J. Mol. Struct., 742,215

Müller, H. S. P., Thorwirth, S., Roth, D. A., \& Winnewisser, G. 2001, A\&A, 370, L49
Nummelin, A., Dickens, J. E., Bergman, P., Hjalmarson, Å., Irvine, W. M., Ikenda, M., \& Ohishi, M. 1998, A\&A, 337, 275

Ohishi, M., Ishikawa, S.-I., Amano, T., Oka, H., Irvine, W. M., Dickens, J. E., Ziurys, L. M., \& Apponi, A. J. 1996, ApJ, 471, L61

Pickett, H. M., Poynter, R. L., Cohen, E. A., Delitsky, M. L., Pearson, J. C., \& Müller, H. S. P. 1998, J. Quant. Spectrosc. Radiat. Transfer, 60, 883

Requena-Torres, M. A., Martín-Pintado, J., Rodríguez-Franco, A., Martín, S., Rodríguez-Fernández, N. J., \& de Vicente, P. 2006, A\&A, 455, 971 (Paper I) Rodríguez-Fernández, N. J., et al. 2000, A\&A, 356, 695

Rodríguez-Fernández, N. J., Martín-Pintado, J., Fuente, A., de Vicente, P., Wilson, T. L., \& Hüttemeister, S. 2001, A\&A, 365, 174

Tielens, A. G. G. M., \& Hagen, W. 1982, A\&A, 114, 245

Tielens, A. G. G. M. 2005, The Physics and Chemistry of the Interstellar Medium (Cambridge: Cambridge Univ. Press)

Watanabe, N. 2005, in IAU Symp. 231, Astrochemistry: Recent Successes and Future Challenges, ed. D. C. Lis, G. A. Blake, \& E. Herbst (Cambridge: Cambridge Univ. Press), 415 